\title{
Os principais tipos de materiais magnéticos e o princípio de exclusão de PAULI
}

\author{
Pâmella Gonçalves Barreto ${ }^{1}$, Antonio Eduardo Alexandria de Barros² \\ 1,2 Universidade Federal do Tocantins (UFT)
}

Palavras-Chave: Eletromagnetismo, Ensino de Física, Materiais Magnéticos.

\section{Introdução}

Os materiais magnéticos desempenham um papel importante na economia mundial e no desenvolvimento de novas tecnologias, pois possuem aplicações em produtos e processos industriais. Suas utilizações vão desde dispositivos com funções simples até componentes sofisticados utilizados na indústria eletroeletrônica (RODRÍGUEZ, 1998). Apesar dessa importância, os materiais magnéticos e suas características são praticamente desconhecidos por grande parte dos professores e alunos, principalmente do ensino básico e uma das causas é a lacuna deixada pelos livros didáticos, deste nível de ensino. Baseado neste fato, este trabalho visa abordar, em um contexto clássico, as principais características que envolvem os principais tipos de materiais magnéticos: os diamagnéticos (D), paramagnéticos (PM), ferromagnéticos $(F M) \quad e$ antiferromagnéticos (AF) visando colaborar/complementar o estudo do eletromagnetismo.

\section{Metodologia e material}

Este trabalho busca suprir uma inconsistência encontrada nos livros didáticos do ensino médio sobre a origem atômica do eletromagnetismo nos materiais, através da confecção de um material educacional na forma de livro complementar, baseado na aprendizagem significativa de D. Ausubel.

O principal objetivo deste material é ser potencialmente significativo, ou seja, ser uma ferramenta que desperte o interesse e promova uma aprendizagem que passe a fazer parte do cognitivismo do leitor. Para isso, o livro traz experimentos de fácil realização, simulações computacionais, abordagens relacionadas à história das ciências, mapas conceituais, entre outros. Portanto, ele apresenta várias ferramentas que podem ser facilmente compreendidas, utilizadas e reproduzidas, de acordo com a realidade do leitor.

\section{Resultados e discussão}

Com intuito de simplificar a explicação sobre os principais tipos de materiais magnéticos aos leitores que nunca tinham cursado a disciplina de Eletromagnetismo, tanto do Ensino Médio (EM) quanto da graduação, teve-se a ideia de utilizar como base um dos conceitos discutidos desde o primeiro ano do EM, o Princípio de Exclusão de Pauli. Este princípio estabelece que num mesmo átomo, dentro de um orbital, não há elétrons com mesmos números quânticos, ou seja, que férmions idênticos não ocupam o mesmo estado quântico. Fazendo um paralelo entre os elementos da tabela periódica e a distribuição eletrônica deles, percebeu-se que quando os spins eletrônicos estão compensados (um "up" e um "down"), em um orbital pertencente ao subnível de maior energia, as propriedades magnéticas do material não são significativas, porém o são quando há desemparelhamento eletrônico (somente "up"). Isto comprova que a origem atômica do magnetismo nos materiais está relacionada com o spin do elétron e com o seu orbital, possibilitando diferenciar materiais diamagnéticos de paramagnéticos, conforme a Figura 1.

Os átomos dos materiais $D$ possuem orbitais completos no subnível mais energético, portanto seus momentos magnéticos de spin não contribuem para a magnetização desses materiais. Sua suscetibilidade magnética é negativa e sua permeabilidade relativa é ligeiramente menor do que um. Elas são quase independentes da temperatura. O diamagnetismo é uma forma muito fraca de magnetismo. Ele não é permanente e persiste somente enquanto um campo magnético externo está sendo aplicado (CALLISTER; WILLIAM, 2008). A magnitude do momento magnético induzido é extremamente pequena e em uma direção oposta àquela do campo que foi aplicado. Nesses materiais, não há a contribuição do spin do elétron, apenas da variação do movimento orbital do elétron provocada pela atuação deste campo magnético externo. 


\section{Anais do I Encontro Regional do MNPEF Centro-Oeste/Norte \\ Brasília, DF - 11 a 12 de julho de 2019 \\ v. 3, n. especial (2019): Revista do Professor de Física \\ ISSN 2594-4746 (on-line)}

Os átomos dos materiais PM possuem elétrons desemparelhados no subnível mais energético. Eles somente apresentam magnetização na presença de um campo magnético externo. Isso se deve a distribuição aleatória dos momentos magnéticos, que somente se orientam na presença desse campo, tendo o mesmo sentido dele. A magnetização apresentada por esses materiais é fraca e tem contribuição do momento orbital e do spin do elétron. Como os momentos de dipolos magnéticos se alinham com o campo externo, há um aumento da magnetização, dando origem a uma permeabilidade relativa maior que a unidade e a uma suscetibilidade magnética relativamente pequena e positiva. A tendência ao alinhamento encontra oposição na agitação térmica, assim a susceptibilidade magnética deve depender da temperatura, diminuindo quando esta aumenta.

Figura 1 - Configuração eletrônica de spin do Berílio e do Oxigênio.

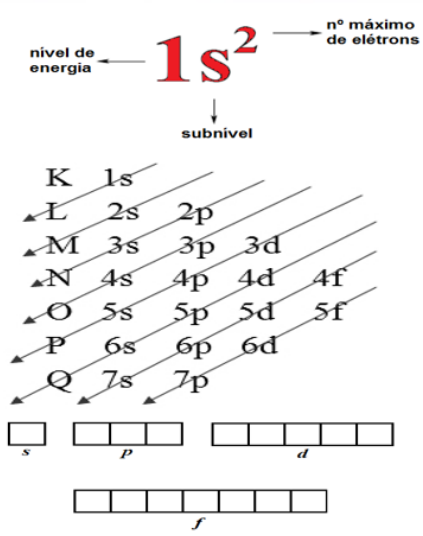

Materiais Diamagnéticos

Configuração eletrônica do berílio (Be)

(Número atômico 4)

$1 \mathrm{~s}^{2} 2 \mathrm{~s}^{2}$

$\underset{\uparrow \downarrow}{1 s^{2}} \frac{\uparrow \downarrow}{2 s^{2}}$

Materiais Paramagnéticos

Configuração eletrônica do oxigênio (O)

(Número atômico 8)

$1 \mathrm{~s}^{2} 2 \mathrm{~s}^{2} 2 \mathrm{p}^{4}$

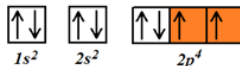

Fonte: Autores.

Entretanto, quando se conhece a susceptibilidade magnética do material junto com a distribuição eletrônica dele, obedecendo o Princípio de Exclusão de Pauli, consegue-se classificar os materiais em D, PM, FM ou AF.

Os materiais FM e AF possuem spins desemparelhados em seu subnível mais energético e a susceptibilidade magnética deles é muito maior do que zero para o caso dos FM e nula para os AF. Estes materiais podem alterar suas propriedades magnéticas dependendo da temperatura, tornando-se um material paramagnético: ao atingirem a temperatura de Curie (FM) e ao atingirem a temperatura de Néel (AF).

\section{Conclusões}

Este trabalho mostrou ser possível ensinar e explicar temas da Física desenvolvidos e pesquisados no mundo acadêmico numa linguagem simples, clara e objetiva utilizando conceitos específicos de nível médio. Desta forma, espera-se que qualquer leitor deste nível consiga aprender a identificar os principais tipos de materiais magnéticos e perceber que o eletromagnetismo está presente no interior dos materiais e não somente ligados às correntes elétricas em circuitos.

\section{Agradecimentos}

O presente trabalho foi realizado com o apoio da Coordenação de Aperfeiçoamento de Pessoal de Nível Superior - Brasil (CAPES).

\section{Referências}

CALLISTER, JR., WILLIAM D. Ciência e Engenharia dos Materiais: Uma Introdução. 5 ed. Rio de Janeiro: Editora LTC, 2008.

RODRÍGUEZ, G. J. B. O Porquê de Estudarmos os Materiais Magnéticos. Revista Brasileira de Ensino de Física, v. 20, n. 4, p. 315-320, 1998. 